\title{
A simple voice communication using the modulation of the reflected
}

\section{light}

\author{
Akram N. Mohammed, Yasir A. Ali, Duaa S. Jbaier \\ Department of Applied Science, University of Technology, Baghdad, Iraq \\ E-mail: akram.noori@gmail.com
}

\begin{abstract}
There is no adopt in the importance of the optical communications in scientific civil and military applications because of it's simplicity in manufacturing and it's low cost. The method of optical communication depends upon bearing the light beam the translated informations by a method called the light modulation. This method depends upon changing some light properties as frequency, amplitude and pulse duration according to the translating informations. The changes in the first two properties are concerned optically with the analog modulation while the third one concern at most with digital modulation. All past methods are expensive with low efficiency and needs electrical or magnetic fields. In this technique the source of voice used a source of emitting light at the same time. This was done by using a reflecting microphone to reflect the incident laser beam to the receiver which was an photocell which connected to an audio amplifier. The emitting voice was clear without any type of noise with very high efficiency.
\end{abstract}

Key words

Communication by reflection simple technique high quality.

Article info.

Received: Dec. 2017

Accepted: Feb. 2018

Published: Sep. 2018

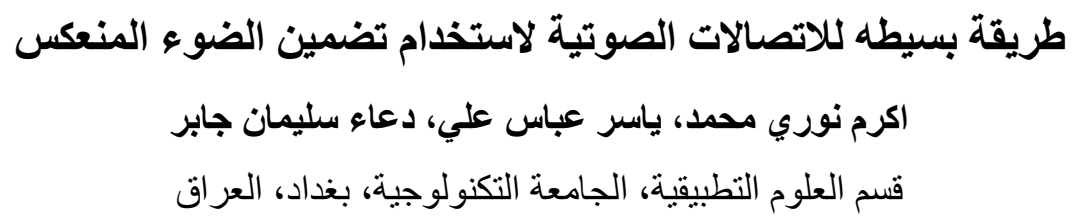

الخلاصة

لا شك في أهمية الاتصالات البصرية في الحياة العامة و التطبيقات العسكرية وذللك لسهولتها وقلة تكاليفها.

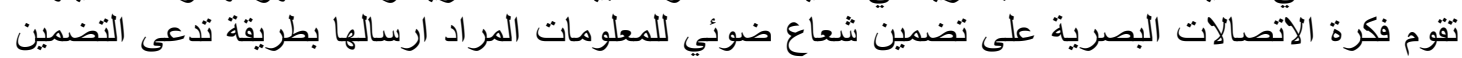

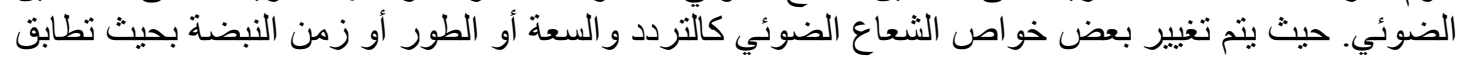

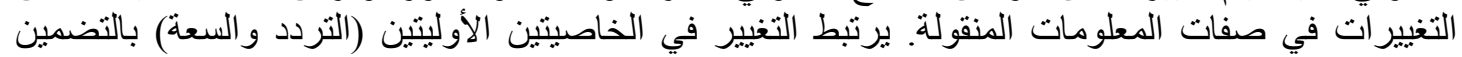

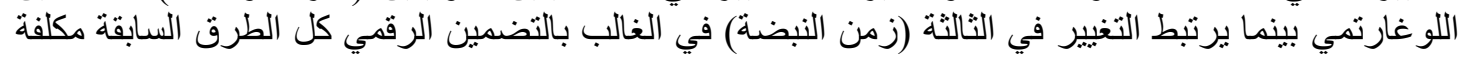

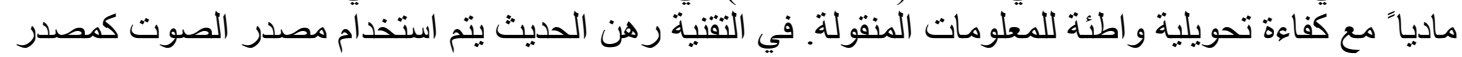

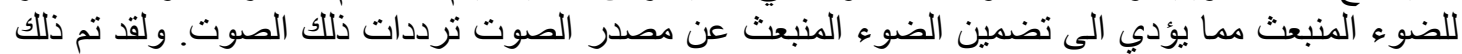

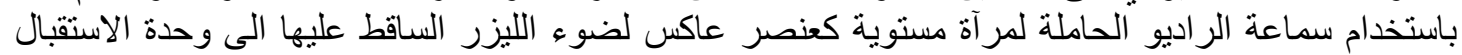

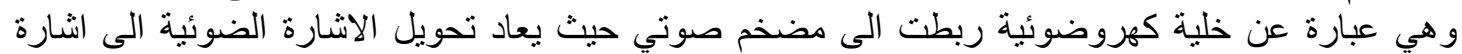
صوتية واضحة تمام الوضوح ح. الاشكال المرفقة و التصاميم المستخدمة في دراسة نتائج هذه الطريقة لتحقيق كافة التانة

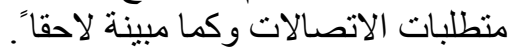

\section{Introduction}

Communication modulation is the process by which some characteristic of a carrier wave is made to vary in accordance with an information -bearing signal wave (The modulating wave [1]. 


\section{Theory}

There is a fine similarity in many aspects between light and voice waves. One of these similarities what known as Doppler effect.

If light or sonic wave with a frequency/ incident on a vibrating body (mechanical motion), the reflected wave will has a new frequency $f \pm \Delta f \quad[2,3,4]$ change in wave frequency $\mathrm{A} f$ will be of a constant value if the vibrating body has a constant motion, and a variable value if the motion was variant. That change in frequency because of that collision called Doppler Effect.

\section{Types of modulations}

\section{1- Amplitude Modulation (AM)}

In this system the intensity or amplitude of the carrier wave (light wave) varies in accordance with the modulating signal wave.

The modulating field (electric or magnetic) rotate the plane of polarization of the incident polarized wave by an amount depending upon the transmitting signal frequency changes. The output wave passed through another polarizer (which has a plane of polarization parallel to the plane of polarization of the first polarizer) which we call the analyzer. The analyzer will allow some part of the modulated wave to pass through, causing a low transmitting efficiency.

\section{2- Frequency Modulation (FM)}

In frequency modulation (FM) the frequency of the earner wave is varied in such a way that change at any instance is proportional to another signal that varies with time. This means a change in receiving wave phase. This what happen really in Doppler effect, so it calls also phase modulation.

\section{3- Code modulation}

Pulse modulation involves modulating a carrier that is a train regularly recurrent pulses. The modulation might vary the amplitude (PAM or Pulse amplitude modulation), the duration (PDM or Pulse duration modulation) or presence of the pulses (PCM or Pulse code modulation [1].

\section{Results and discussion}

In order to avoid all known problems in acousto-optic (AO) and acoustic electro-optic (AEO) modulations the opt-mechanical technique was used. This technique depends upon making the vibrating body as a source of emitting light. This was done by adhesion a plane mirror on the face of the radio speaker. When the laser beam incident on that mirror it will be reflected to far photodiode (see Fig. 1), which connected to an amplifier and later to another speaker. 


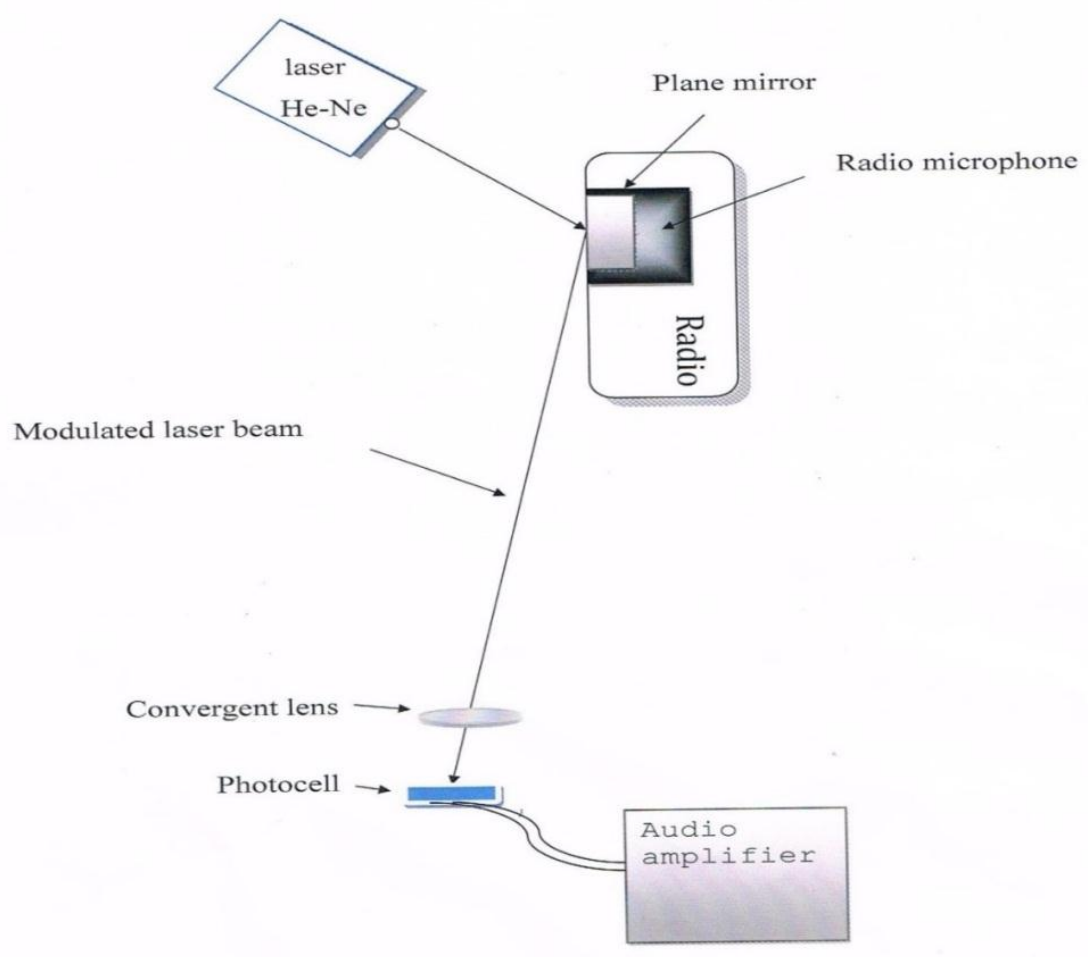

Fig. 1: Explaining graph of the experiment.

When the radio work the mirror will vibrate by the same frequency as the microphone do, so the incident laser beam will suffer the same changes in frequency as the speaker done. This will be clear in receiving voice by the second speaker.

Fig. 2 shows another arrangement of experiment where the vibrating wave incident on another mirror used to change the direction of sending. There is no change notice in efficiency.

Fig. 3 shows the third type of our experiment when we spilt the laser beam by Fresnel biprism and sending them to two receivers. The receiving wave had a good efficiency. 


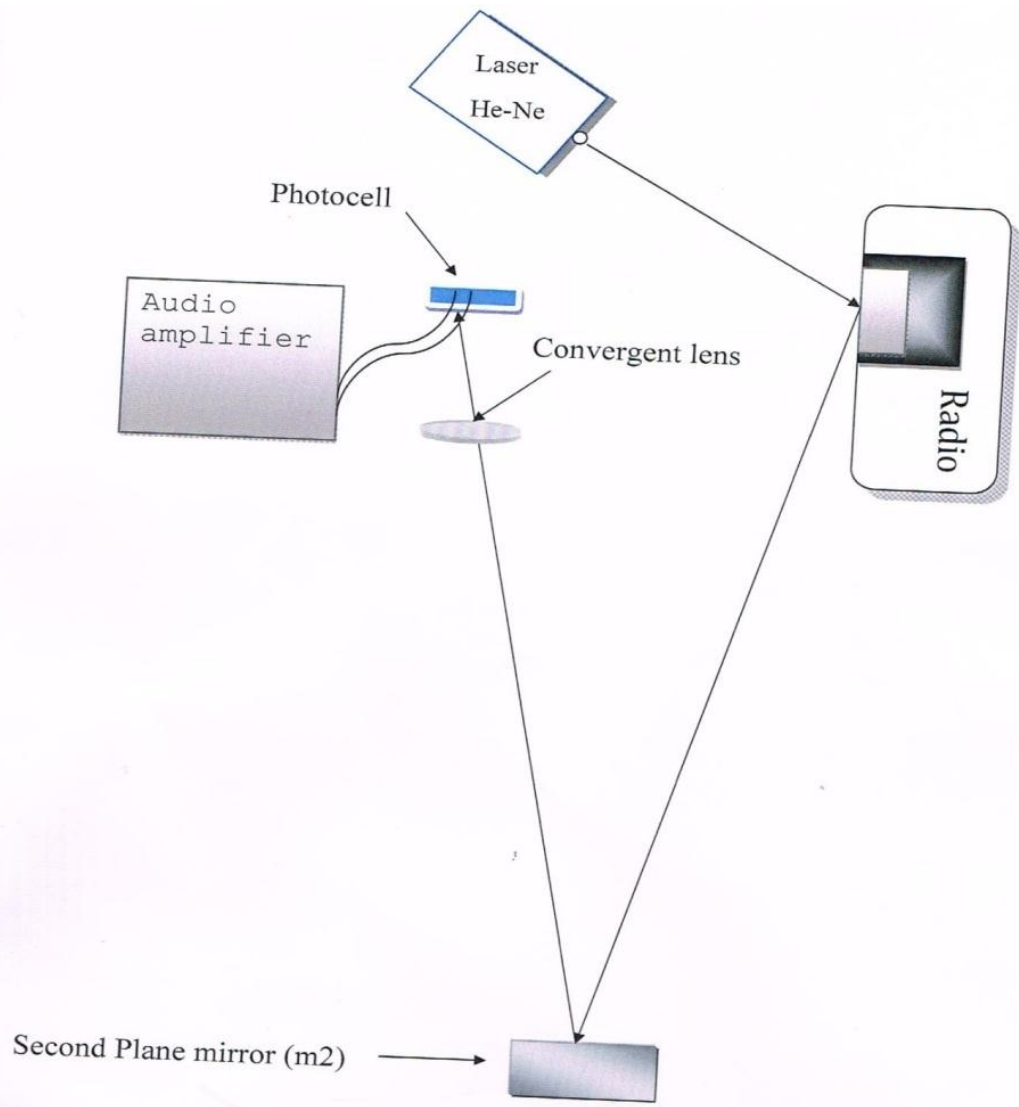

Fig. 2: Experimental setup using a flat mirror (2).

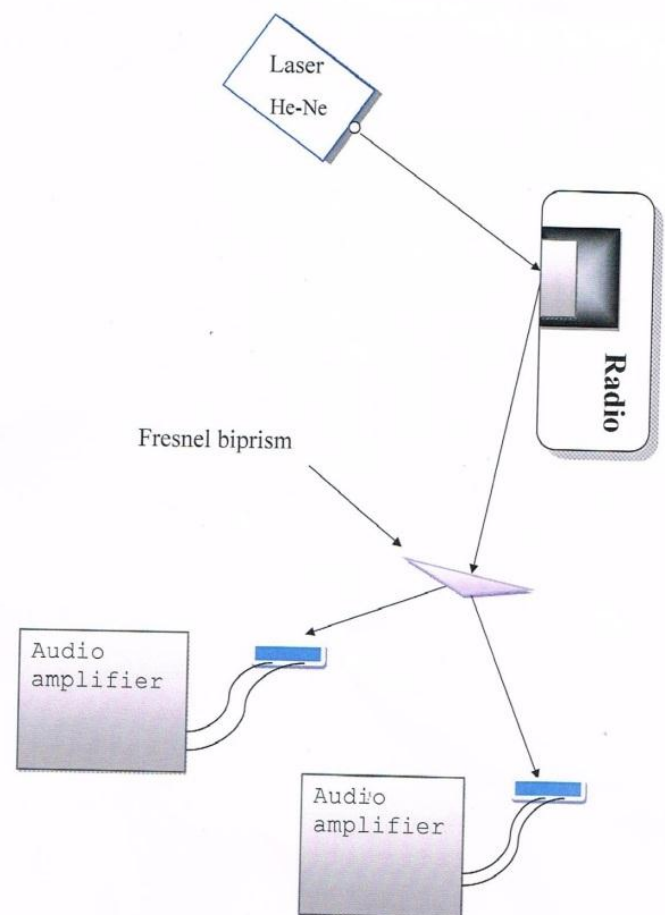

Fig. 3: Experiment setup using Fresnel biprism. 


\section{The system efficiency calculations}

The efficiency is defined as the ratio between the received and the emitted powers. This factor in communication is affected by many factors as fog, rain, snow, scattering, light interference ....etc [5]. All these factors are summed in one term called the attenuation (A). But the main reason that affect the transmitted beam intensity is depend upon the place of work, i.e., in cold countries the main reason that optical communication ranges have been limited to non-commercial telecommunications function is fog $(10-100) \mathrm{dB} / \mathrm{km}$ attenuation.

In our country the scattering due to dust in our atmosphere [6]. In order to measure attenuation which limited the efficiency we have to use LambertBeers law as follows:

$T=\exp \left(-\alpha_{e} L\right)$

where: $\quad T=$ The atmosphere transmittance'.

$\alpha_{e}=$ The attenuation coefficient in $\mathrm{km}^{-1}$.

$L=$ The transmitting range in $\mathrm{km}$.

$\alpha_{e}$ is the total attenuation factor where

$$
\alpha_{e}=\alpha_{\text {scat }}+\alpha_{\text {fog }}+\alpha_{\text {rain }}+\alpha_{\text {snow }}+\alpha_{\text {int. }}+\alpha_{\text {smoke }}
$$

In our country since scattering factor due to dust is the most effected factor we shall take it in our count.

The mathematical relation which used for our research is $[7,8]$ :

$T=\frac{I_{r}}{I_{0}}$

where

$I_{r}=$ Received intensity.

$I_{0}=$ The emitting intensity.

From Eqs. (1 and 2) we get:

$\alpha_{e}=\frac{\ln \left(I_{r} / I_{0}\right)}{L}$

In general the attenuation is represented as:

Attenuation $\left(A_{10}\right)=-10 \log \frac{I_{\text {rec }}}{I_{\text {tran }}}$

For visible and near infrared wavelengths another factor is used to represent the system efficiency. This factor is called visibility ( $\mathrm{V} \mathrm{km})$.

$$
q=\left\{\begin{array}{l}
1.6 \text { if } V>50 \mathrm{~km} \\
1.3 \text { if } 6 \mathrm{~km}<V<50 \mathrm{~km} \\
0.16 V+0.34 \text { if } 1 \mathrm{~km}<V<6 \mathrm{~km} \\
V-0.5 \text { if } 0.5 \mathrm{~km}<V<1 \mathrm{~km} \\
1.3 \text { if } V<0.5 \mathrm{~km}
\end{array}\right.
$$


For our country since the scattering is the measure affected factor in optical communications Eq. (5) became as:

$\frac{A_{10}}{L}=\alpha_{\text {scatt. }}=0.4343 \alpha_{e}$

From Eqs. (7 and 8) we have:

$$
V=\frac{3}{\alpha_{e}}\left(\frac{\lambda}{550}\right)^{-q}
$$

In general the transmittance efficiency is given as:

Effeciency $=\frac{I_{\text {rec }}}{I_{\text {tran }}} \times 100$

Table 1 explains measurements in different weathers.

Table 1 shows one that the efficiency of the two wavelengths $(650 \mathrm{~nm}$ and $532 \mathrm{~nm}$ ) are nearly equal although there great difference in their output powers $P_{650}=100 \mathrm{~mW},\left(P_{532}=1000 \mathrm{~mW}\right)$,

the main reason is that the scattering for shorter wavelength is larger than that for longer wavelengths.

While due to wide band of red and near-IR the effect of light interference during Sundays is greater than that their effects in $\lambda=532 \mathrm{~nm}$ while in night communications this effect reduced for $\lambda=650 \mathrm{~nm}$. The left column in table 1 explained that fact.

$\mathrm{He}-\mathrm{Ne}$ laser has very short range because its low emitting power which push us to use another laser light sources. Two diode lasers were used (A, $\mathrm{i}=650 \mathrm{~nm}, \mathrm{P}=100 \mathrm{mw}$, and $\mathrm{A}$, $2=532 \mathrm{~nm}, \mathrm{P}=1$ watt).

First we checked their efficiency by our system for different distances. These results are represented in Table 1. Then we turn to send our voice through our new system which consisted of a translator and receiver units.

The translator units consists of an amplifier (Teli TB-288A type, China) connected to a speaker, mono-internal speaker which holding a plane mirror (our reflector), and diode laser. While the receiver unit consists of an amplifier (Teli TB-188A type, China) with a loud speaker, photo diode, satellite dish which coated by a Nickel layer to focus the reflected light on the photodiode.

The receiving voice has high range and too clear.

Table 1: The system efficiency for different distances.

\begin{tabular}{|c|c|c|c|c|c|c|}
\hline \multirow{2}{*}{ Distance } & \multicolumn{2}{|c|}{ Efficiency at sunny day } & \multicolumn{2}{c|}{$\begin{array}{c}\text { Efficiency at clouded and } \\
\text { rain day }\end{array}$} & \multicolumn{2}{c|}{ Efficiency at clear night } \\
\cline { 2 - 7 } & $\lambda_{1}=650 \mathrm{~nm}$ & $\lambda_{2}=532 \mathrm{~nm}$ & $\lambda_{1}=650 \mathrm{~nm}$ & $\lambda_{2}=532 \mathrm{~nm}$ & $i_{1}=650 \mathrm{~nm}$ & $z_{2}=532 \mathrm{~nm}$ \\
\hline 0 & 80 & 80 & 100 & 100 & 100 & 1.00 \\
\hline 30 & 76 & 78 & 100 & 100 & 99 & 99 \\
\hline 60 & 74 & 76 & 99 & 99 & 98 & 98 \\
\hline 90 & 72 & 74 & 98 & 98 & 97 & 97 \\
\hline 120 & 70 & 72 & 96 & 96 & 96 & 94 \\
\hline 150 & 68 & 70 & 90 & 94 & 95 & 92 \\
\hline 180 & 65 & 67 & 88 & 90 & 92 & 90 \\
\hline
\end{tabular}




\section{Conclusion}

1- Our experiment give an ability of building a new type of telecommunication. This can be done by using a cordless microphone with the hand speaker emitting infromations to the speaker-phone includes the plane mirror reflect the laser beam to an optical fiber for (earth linking) or through the space to the receiver. The receiver will receive information by a cordless phone and emit his information's by the same way by a system of the same design.

2- Another possible application as we expect is more important this is sending an ultrasonic wave through a fiber optics to open the closed artery of the hearts. This will need another study above our lab. ability.

\section{References}

[1] D. Psaltis, H. Lee, G. Sirat, Applied Physics Letters, 46, Feb. 1 (1985) 215217.

[2] Alonso, Marcelo, Edward J. Finn. Student workbook to physics. P 550, Addison-Wesley, 1970.

[3] Jurgen R. Meyer-Arendt, M. D. Introduction to classical and mondem optic P.532, Second Addition 1984.

[4] Herb Gottlieb, More than 101 ways to use a laser, Section 81 applications, Doppler effect, C 2000, Metrologic instrument Inc., Black Wood, New Jersey. 08012.
[5] R. Ramirez Iniquez and S. M. Idrus CRC Press, (2008) 26-40.

[6] Ramain, M. larkin, G. Ghayel, B. Paulson, G. Nykolak, "Optical wireless propagation, theory vs. Experiment" optical wireless communication III, proc. SPIE, vol. 4214, 2001.

[7] R.L. Freman, "Telecommunication Transmission handbook," $3^{\text {rd }}$ edn. John Wiley \&Sons, Inc. USA (1991).

[8] I. I. Kim, B. Mc Arther, E. J. Korevaar, "Communication of laser beam propagation at $785 \mathrm{~nm}$ and 1550 $\mathrm{nm}$ in fog and haze for optical wireless communication," In optical wireless communication III, Interband Society for Optics and Photonics vol. 4214 pp.26-28.

[9] M. S. Khan, M.S. Khan, N. R. Naqvi, M.A. Khan, M.latif, K.Ullah, R.D. Khan, R. Wali, E. leitgep, "Optical Attenuation Estimation from Measured Visibility Data in Islamabad-Pakistan," In Network and Optical Communication (NOC), $18^{\text {th }}$ European Conference on and Optical Cabling and Infrastructure (oc and i) pp203-208 (2015).

[10] P. W. Krusel, L. D. Mc Glauchlin, R. B. Mc Quistan, "Elements of Infrared Technology: Generation, Transmission, and Detection" Wiley Hoboken, NJ (1962). 